This document is the accepted manuscript version of the following article:

Barrett, F., McRoberts, R. E., Tomppo, E., Cienciala, E., \& Waser, L. T.

(2016). A questionnaire-based review of the operational use of remotely sensed

data by national forest inventories. Remote Sensing of Environment, 174,

279-289. https://doi.org/10.1016/j.rse.2015.08.029

This manuscript version is made available under the CC-BY-NC-ND 4.0

license http://creativecommons.org/1icenses/by-nc-nd/4.0/

\title{
A questionnaire-based review of the operational use of remotely sensed data
} by national forest inventories

Frank Barrett ${ }^{1}$, Ronald E. McRoberts ${ }^{2}$, Erkki Tomppo ${ }^{3}$, Emil Cienciala ${ }^{4}$, Lars T. Waser ${ }^{5}$

${ }^{1}$ Irish Forest Service, Department of Agriculture, Food and the Marine, Wexford, Republic of Ireland

${ }^{2}$ Northern Research Station, U.S. Forest Service, Saint Paul, Minnesota, USA

${ }^{3}$ Natural Resources Institute Finland (Luke), Vantaa, Finland

${ }^{4}$ IFER - Institute of Forest Ecosystem Research, Jilove u Prahy, Czech Republic

${ }^{5}$ Swiss Federal Institute for Forest, Snow and Landscape Research, WSL, Birmensdorf, Switzerland

Abstract. We report on the operational use of remotely sensed data by national forest inventory (NFI) programmes in 45 countries representing approximately $65 \%$ of the world's forest area. The analysis is based on responses to a questionnaire prepared under the auspices of COST Action FP1001 "Improving Data and Information on the Potential Supply of Wood Resources: A European Approach from Multisource National Forest Inventories (USEWOOD)”.

Responses were received from NFI remote sensing experts from both European and non-European countries. Three major conclusions were drawn from the study: (1) remote sensing now plays an essential role in many NFI programmes and provides data that can be used to enhance estimates for the most meaningful and commonly reported forest resource parameters; (2) a wide spectrum of remote sensing methods are currently used by NFI teams; and (3) although substantial effort and attention has been focused on the use of aerial photography and 
spaceborne sensor data for mapping and enhancing estimation, integration of uncertainly estimation requires additional attention.

The operational use of remotely sensed data by NFI programmes is

32 illustrated for three case studies: a case study for Switzerland focuses on digital aerial photography, a case study for Finland focuses on spaceborne sensor data for small area estimation, and a case study for the USA focuses on spaceborne sensor data for increasing the precision of large area estimates. Although use of remotely sensed data by NFI programmes may remain region-specific and some approaches are not readily transferable, generally applicable good practice guidelines were

38 formulated on the basis of the questionnaire responses and the case studies. These guidelines are intended to promote better use of limited financial resources and to increase the accuracy and precision of NFI estimates.

\section{Introduction}

43 Capitalizing on development work spanning several decades and in some 44 cases more than 100 years, technologically advanced national forest inventory 45 (NFI) programmes using statistical sampling have been established in many 46 European and non-European countries (Tomppo et al., 2008a,b, 2011; Lawrence 47 et al., 2010). The earliest NFIs were established in the Nordic countries and the 48 United States of America (USA) and focused on the continued availability and 49 supply of timber with an emphasis on acquiring information related to forest area, 50 volume and growing stock increment (LaBau et al., 2007; Tomppo et al., 2008a,b, 51 2011). Later, NFI programmes introduced new variables and new sample designs 
52 to estimate non-timber attributes related to biodiversity (e.g., naturalness, forest

53 structure, deadwood volume) and forest health (e.g., crown vitality, defoliation)

54 (Tomppo et al., 2010, NFI Report Chapters 1-37).

55 NFI plot-based, in situ surveys integrated with aerial photography and 56 spaceborne sensor data both serve the requirement for ever more diverse and 57 detailed forest statistics and produce relevant spatially explicit products. Remotely 58 sensed data have been incorporated into operational forest inventories, and 59 estimates enhanced through the use of remote sensing-based maps can now be 60 expressed in forms similar to sample-based estimates. McRoberts and Tomppo 61 (2007) list four primary ways by which remote sensing approaches enhance NFIs: 62 (1) providing faster and less expensive methods for estimating forest attributes;

63 (2) increasing the accuracy of large area inventory estimates, often via stratified or 64 weighted estimation; (3) providing inventory estimates with acceptable bias and 65 precision for small areas for which sufficient field data are not available; and (4) 66 producing forest thematic maps that can be used for purposes such as timber 67 production, procurement, and ecological studies. Historically, interpretation and mapping of trees and stands based on aerial 69 photography have represented the most popular form of remote sensing of forests 70 (Spurr, 1960). Aerial photography is the oldest and most frequently used form of 71 remote sensing and was first used to aid stratification during the 1940s and 1950s 72 by the Forest Inventory and Analysis (FIA) programme of the U.S. Forest Service 73 (Bickford, 1952; LaBau et al., 2007) and by Spain and Switzerland in the 1960s 74 and late 1970s, respectively (Martinez \& Condes, 1997; Brassel \& Lischke, 
75 2001). The increasing availability of aerial photography in digital formats and the

76 ease of integration with auxiliary and other GIS data has greatly facilitated its use

77 (McRoberts \& Tomppo, 2007). From an operational perspective, considerable

78 cost savings may be realised by initially observing NFI plot locations using aerial

79 photography or high resolution satellite imagery.

80 NFI country reports (Tomppo et al., 2010) and other surveys (Köhl \&

81 Päivinen, 1996) indicate that aerial photography continues to be widely used by

82 European NFI programmes. Koch (2013) identifies multiple reasons for continued

83 use of aerial photography: (1) long tradition; (2) fine spatial resolution;(3) greater

84 probability of acquiring cloud free data within a specific time window; (4) close

85 cooperation between survey institutes acquiring photography and forest

86 authorities; (5) relatively large costs for very high resolution satellite data; and (6)

87 the relative ease of capturing smaller European survey areas using aerial

88 photography when compared to larger non-European countries such as the USA,

89 Canada, or in South America.

90 In countries outside Europe, NFI use of earth observation data from

91 satellites is more common (Lawrence et al., 2010; FAO, 2008; Koch, 2013). The

92 integration of remotely sensed satellite data with field inventory data for the

93 estimation of forest parameters dates back to the 1980s (e.g. Poso et al., 1984;

94 Halme \& Tomppo, 1987; Danson, 1987; Tomppo, 1988). Techniques such as the

95 k-nearest neighbours (k-NN) method were subsequently refined and further

96 developed for regional applications in the USA (Franco-Lopez et al., 2001;

97 McRoberts et al., 2002a) and operationally at national scales in Finland and 
98 Sweden in the 1990s and 2000s (Reese et al., 2003; Tomppo et al., 2008a). The

99 opening of the Landsat archive, making the entire historical time series of data

100 freely available, greatly facilitated the use of satellite imagery (Loveland \& 101 Hansen, 2012). Satellite-based methods were first implemented operationally as 102 part of the Finnish multi-source NFI (MS-NFI) by Tomppo in the early 1990s 103 (Tomppo, 1991; Tomppo et al., 2011). Similar approaches to those in Finland and 104 the USA for integrating NFI and field plot data with Landsat data have been tested 105 in Norway (Gjertsen, 2007), Ireland (McInerney et al., 2005), Austria (Koukal et 106 al., 2007), Italy (Maselli et al., 2005) and Brazil (Vibrans et al., 2013).

107 Other earth observation systems, such as synthetic aperture radar (SAR) or 108 polarimetric SAR interferometry (Praks et al., 2007; Hajnsek et al., 2009) have 109 been tested and used to estimate forest variables over large areas. In particular, the 110 use of airborne laser scanning (ALS) data in combination with NFI plot 111 information has increased in recent years and has been shown to be effective for 112 enhancing the estimation of forest inventory attributes (Naesset, 2007; Vastaranta 113 et al., 2013; Wulder et al., 2013; McRoberts et al., 2013). Although data from 114 these sensors have yet to be used operationally by NFIs, they are used 115 operationally for forest management inventories in Finland, Norway and Sweden. 116 Despite the increasing operational use of remotely sensed data by NFIs, 117 practical information on the detail, scale and approaches used has not been readily 118 available in a consistent format. Therefore, one of the overall objectives of COST 119 Action FP1001 "Improving Data and Information on the Potential Supply of 120 Wood Resources" was to provide such information. COST (European 
121 Cooperation on Science and Technology) is a European framework for promoting

122 and facilitating scientific cooperation among European scientists and researchers

123 (COST, 2014). COST Action FP1001 focused on European approaches for using

124 MS-NFI data to improve information on the potential supply of wood resources

125 (COST FP1001, 2014). The specific objectives of the study reported herein were

126 threefold: (1) to summarise information on the operational use of remotely sensed

127 data by both European and non-European countries via responses to a

128 questionnaire survey; (2) to illustrate state-of-the-art remote sensing support for

129 NFIs via case studies; and (3) to provide good practice guidelines for use of

130 remotely sensed data by NFIs based on responses to the questionnaire and the

131 case studies.

132

133 2. Materials and methods

134 A review, assessment and classification of remote sensing methods as used 135 operationally in NFIs was conducted by evaluating 37 NFI country reports in 136 Tomppo et al. (2010) and relevant surveys, reports and publications (Köhl \& 137 Päivinen, 1996; Westinga et al., 1999; Köhl et al., 2006; McRoberts \& Tomppo, 138 2007; FAO, 2008; McRoberts et al., 2010; Koch, 2013). A 65-question survey 139 was designed following review of NFI remote sensing methods and suggestions 140 from participants in Working Group 2 (WG2) of COST Action FP1001. The 141 questionnaire was modified and enhanced based on feedback from collaborating 142 WG2 members and included seven thematic areas:

143 (1) personal, organisational data related to the national expert or respondent; 
144 (2) basic information related to the NFI, forest resource assessment of interest;

145 (3) use of aerial photography and associated technologies;

146 (4) use of spaceborne remotely sensed data and associated technologies;

147 (5) forest attribute maps and derived spatial products generated from NFI data $148 \quad$ with the support of remotely sensed data and technologies;

149 (6) remote sensing software and systems, technical expertise and personnel;

150 (7) current and future development prospects for remote sensing in NFIs.

151 The questionnaire was distributed to WG2 country representatives in 2011 with

152 further follow up to individual countries for updates and/or clarifications in 2012 153 and 2013. In addition, national experts outside the participating COST Action 154 FP1001 countries were contacted to contribute to a more complete global picture 155 of remote sensing use by NFIs.

156 To illustrate the operational use of remote sensing in NFIs we analysed 157 descriptions of the state-of-the-art for three countries: (1) use of digital aerial 158 imagery in Switzerland; (2) use of satellite imagery for small area estimation in 159 Finland; and (3) use of satellite imagery to increase the precision of large area 160 estimates in the USA. Finally, good practice guidelines for the implementation of 161 remote sensing by NFIs were formulated based on the assessment and analysis of 162 the questionnaire responses and the case studies. 


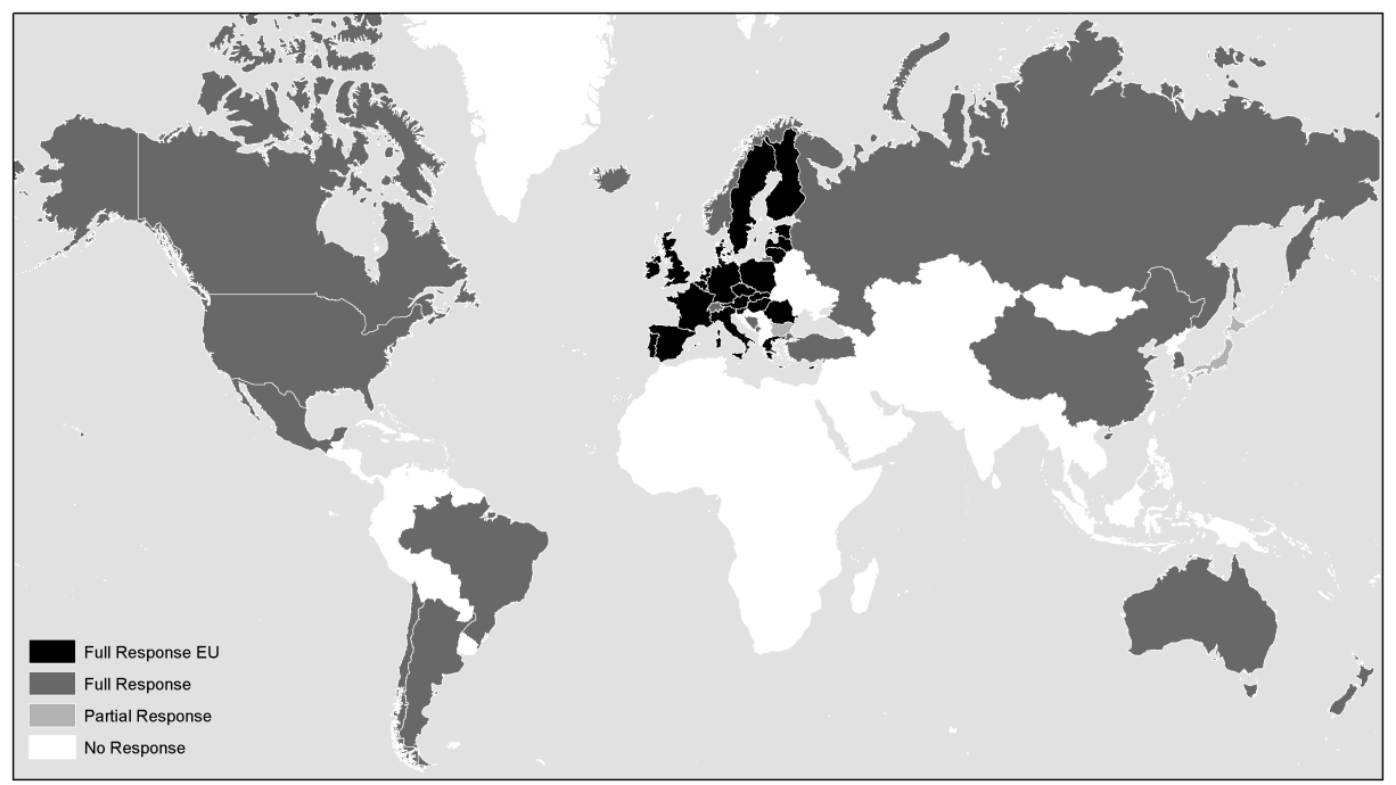

Figure 1. Countries responding to the National Forest Inventory remote sensing

\section{questionnaire.}

\section{Results and discussion}

\subsection{General results}

This study was conducted as a questionnaire survey, with questionnaires submitted to relevant NFI remote sensing experts. Initial drafts of the remote sensing questionnaire were developed, circulated for review by a small group of COST Action members, and subsequently revised. As with previous COST Action surveys of this nature, the results depend on multiple factors: (1) the sampling approach; (2) the influence of non-responses; and (3) the potential of the respondents to correctly answer the questions (Cienciala et al., 2008; Winter et al., 2008). Although the internal review of the questionnaire likely circumvented serious misinterpretations, some data quality problems still occurred such as obvious logic errors or responses inconsistent with other published material 
relating to a particular country's responses (e.g. Lawrence et al., 2010). In obvious

cases these misinterpretations were excluded from the results and treated as missing values; alternatively, respondents were contacted for clarifications and corrections. The questionnaire responses were analysed by assessing the proportions of particular responses to individual questions.

185 Of the 48 countries contacted (Figure 1), 43 responded fully, two responded partially, and only three failed to respond. Based on the FRA 2010 report and forest definitions used by the responding countries, the forest area of the responding countries represented $65 \%$ of the global forest area (FAO, 2010). This estimate includes $99 \%$ of the total forest area of the 28 European Union (EU) countries plus Iceland, Norway and Switzerland (FAO, 2010). Apart from Croatia and Serbia, the responses provided a complete overview of the operational use of remote sensing by European NFIs.

\subsection{Summary of organisational information for questionnaire respondents}

The analysis summarised responses to questions regarding the respondents' organisations as well as basic information pertaining to their NFIs such as sampling designs, and then focused in more detail on the description and operational use of remotely sensed data.

Most countries responding to the survey have completed or are in the

200 process of completing at least one complete national inventory. To date, Finland is 201 conducting its $12^{\text {th }}$ inventory, and Norway is conducting its 10 th inventory. 202 Approximately $98 \%$ of the questionnaire respondents indicated that their 
organisations operate at national, sub-national or local levels, with the vast majority (93\%) indicating that they represented governmental agencies.

205 Approximately $78 \%$ of respondents indicated that their NFI programmes operate 206 in temperate ecological zones, with $24 \%$ of respondents indicating that their 207 programmes also operate within boreal zones. One country, the USA, operates 208 across temperate, boreal and topical (wet, dry) ecological zones. Based on the 209 questionnaire responses, 93\% of countries conduct a sample-based statistical 210 inventory with temporary or permanent sample plots or points located on a grid or 211 tessellation of space. Five countries (11\% of respondents) aggregate stand-level 212 information for their assessment in addition to a statistical sample-based 213 approach.

\subsection{Overview of the use of remotely sensed earth observation data by NFIs} Approximately $71 \%$, or 32 of the 45 countries, consider their NFIs to be 217 dependent or partially dependent on earth observation data (Figure. 2). 218 Approximately $31 \%$ of respondents (14 countries) considered aerial photography 219 indispensable for the completion of their NFI, whereas satellite images were 220 considered as essential by only $13 \%$ and a combination of both satellite images 221 and aerial photos by $9 \%$ of respondents. A further $56 \%$ of respondents considered 222 their NFIs not to be dependent on spaceborne sensors or data, whereas $33 \%$ 223 considered their NFIs not to be dependent on aerial photography. No country 224 indicated operational use of or reliance on data from radar or lidar sensors or unmanned aerial vehicles. 
227 least partially essential and $27 \%$ of respondents consider satellite images to be

228 partially essential for assisting forest area estimation, facilitating field work, 229 validating NFI results or assisting with other operational aspects of their NFI 230 programmes. Approximately $7 \%$ of respondents indicated that local, regional or 231 sub-regional forest parameters cannot be estimated without aerial photography 232 and/or satellite imagery.

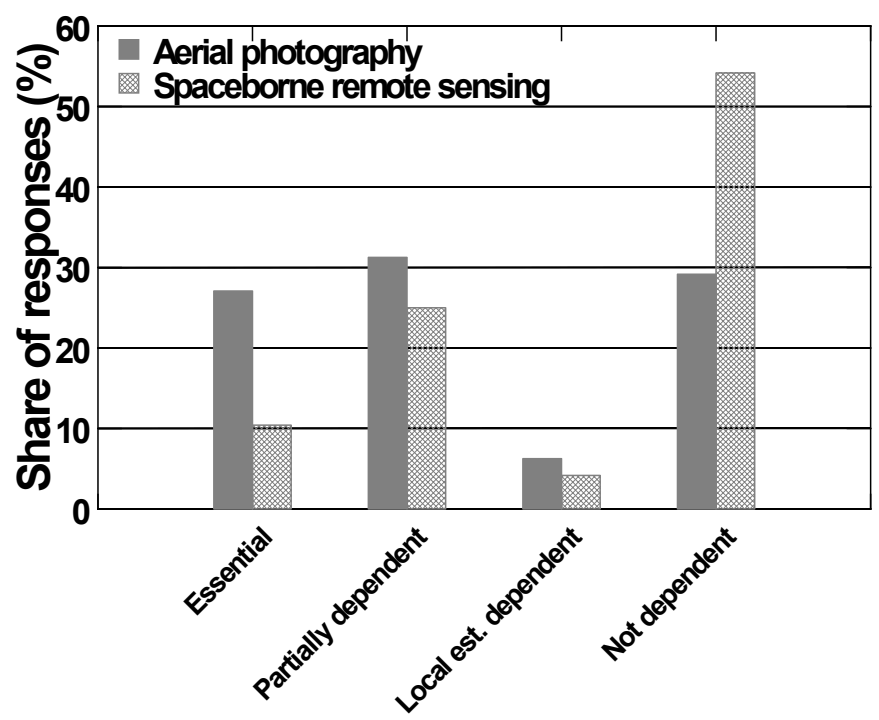

Figure. 2. Dependency on the use of aerial and/or satellite images to complete NFI tasks.

239 forest attribute maps is the most common application reported by responding countries ( $38 \%$ or 17 countries). A further $27 \%$ or 12 countries, conduct double241 or multi-phase sampling for stratification using a combination of aerial 
242 photography, satellite imagery and other auxiliary spatial data such as

243 topographic, land cover/use, and land ownership maps. The primary use of aerial

244 imagery relates to plot-level evaluations such as assessing forest cover, aiding

245 stratification, facilitating field access, and navigation (Section 3.4.2).

246 Approximately $65 \%$ of the respondents (30 countries) construct map

247 products by combining their NFI data and satellite imagery, aerial imagery, or

248 both. The map themes include forest cover and or area (57\%), forest type (57\%),

249 land cover type (41\%), species groups (28\%), biomass $(15 \%)$, and volume of 250 growing stock by tree species or tree species groups (20\%). Maps of forest 251 attributes such as basal area, stem density, age, height, mean diameter, forest 252 productivity, and fertility are constructed by fewer than $10 \%$ of the responding 253 NFI programmes.

254 The relative importance of satellite and aerial imagery is reflected in the 255 time devoted to remote sensing and photogrammetric activities. The NFI 256 programmes of $40 \%$ of respondents or 18 countries commit at least one month per 257 year to these types of analyses. The NFIs of approximately $49 \%$ or 22 countries 258 use outside agencies and or third party research institutes for remote sensing or 259 photogrammetry services that include image processing, image classification, 260 statistical analysis, computer programming, and modelling; 33\% or 15 countries 261 conduct these analyses in-house. Only $26 \%$ or 12 countries indicate that the 262 technologies, methods and processes applied for remote sensing and or 263 photogrammetry can be readily applied or transferred to other organisations or 264 NFI programmes. 
266 enhance estimation of parameters for small areas with few field plots. Two

267 countries use satellite images to enhance these small area statistical estimates, and

268 two countries use both aerial and satellite imagery for this purpose. Post-stratified

269 estimation using map products based on satellite images and field plot data is used

270 to enhance the estimates by five countries (11\% of the respondents).

272 3.4. Use of aerial imagery to support NFIs

\section{3.4.1 Sensor specification and spatial resolution}

274 In some cases, the names or terms adopted in the questionnaire for sensor 275 specification (e.g., film type, colour, RGB) and sensor type (most countries 276 currently use digital sensors) appear to have been confusing to or misinterpreted 277 by respondents. Thus, the following analysis is based on three assumptions 278 regarding questionnaire responses.

279 Firstly, for countries using aerial photography operationally, we assume 280 that digital sensors are used because they are widely available and almost 281 exclusively used currently in aerial imagery acquisition programmes. Some 282 exceptions may arise in cases where a country still uses analogue frame cameras. 283 Thus, the large numbers of "Not Applicable" (18 countries) responses related to 284 aerial photography film type and the "Not Applicable" (14 countries) responses 285 related to the camera or sensor type question are most likely due to the fact that 286 digital sensors are used. Furthermore, it appears that the question related to aerial 287 film type (e.g., colour film versus colour infrared film) was answered in the 
context of current use of digital (stereo) orthophotos and digital multi-spectral sensors.

Secondly, the spatial resolution of aerial imagery used by some countries appears to be rather coarse. Digital sensors with spatial resolution of less than $100-200 \mathrm{~cm}$ is used by five countries. This type of aerial imagery is most likely acquired in combination with finer resolution imagery from the same sensor. Countries with relatively large areas use specific flight heights (high altitudes) with commercially available airborne sensors to generate or update topographic maps.

Thirdly, most countries responding use either digital ortho-images (28 countries) or digital stereo-photos. Both types of aerial imagery formats are combined with auxiliary equipment (e.g., 3D computer screens using polarized eyeglasses) or are used in combination with photogrammetry, remote sensing or GIS software and systems. Paper-based formats such as hard copy aerial photographs or aerial photography film stocks or both are currently used by only three NFI programmes. A total of five countries use both digital and analogue aerial photographic imagery types simultaneously in their NFI programmes.

\subsubsection{Questionnaire responses}

In general, aerial photographs are acquired by national mapping, topographic, cartographic or forest agencies and seldom specifically by an NFI programme or a third party image provider. The overall dependency on the use of aerial images to complete NFI tasks is summarised in Figure 2. 
The primary use of aerial imagery by NFIs relates to plot-level

312 assessments. These assessments include determining if plot locations are on forest

313 land (67\%), facilitating access or navigation to field plots (56\%), and improving

314 forest area estimation based on forest/non-forest stratifications (44\%). In $25 \%$ of

315 the NFI programmes aerial imagery is also used to define or redefine forest types

$316(22 \%)$, to assess forest condition for inaccessible plots $(20 \%)$, to delineate stand

317 boundaries (20\%), to map Other Wood Land (OWL) or Trees Outside Forest

318 (TOF) (20\%), to map disturbed areas (18\%), to update forest maps between

319 inventory cycles (18\%), and to assess other plot-level parameters such as tree

320 density and height (16\%).

321 Based on questionnaire responses, as many as 12 types of attributes are

322 collected from aerial photo plots. In this phase, plots are not actually surveyed in

323 the field, but rather information is collected from aerial photography which serves

324 as a surrogate for field observation. The most frequently assessed attributes are

325 forest/non-forest land use (51\%), forest type (31\%), and dominant tree species

326 (22\%). More specific stand variables such as height, health, crown diameters,

327 regeneration, and stand edge/shape metrics are less frequently assessed $(<11 \%)$,

328 with the exception of crown cover (24\%) and development stage (16\%).

329 TOF and OWL are land use categories that do not satisfy FAO's definition

330 of forest (Foresta et al., 2013). For this questionnaire, OWL was defined to 331 include individual trees, parkland, rows of trees, hedgerows and woody linear 332 features. Overall, 24\% (11 countries) of respondents collect information on TOF 
and/or OWL using aerial photography, whereas $44 \%$ of respondents indicate that 334 their NFI programmes do not collect this type of information. Aerial images have been used operationally in NFIs for many years 336 (Figure 3). Whereas $18 \%$ of respondents have been using aerial photographs for 337 more than 40 years; $20 \%$ of respondents began using aerial photography operationally in their NFIs in the last 5-10 years; and approximately $13 \%$ of 339 respondents began using aerial photography only in the last five years. 340 Approximately $9 \%$ of respondents indicated that their NFIs used aerial 341 photography in the past but switched to satellite imagery or other data sources.

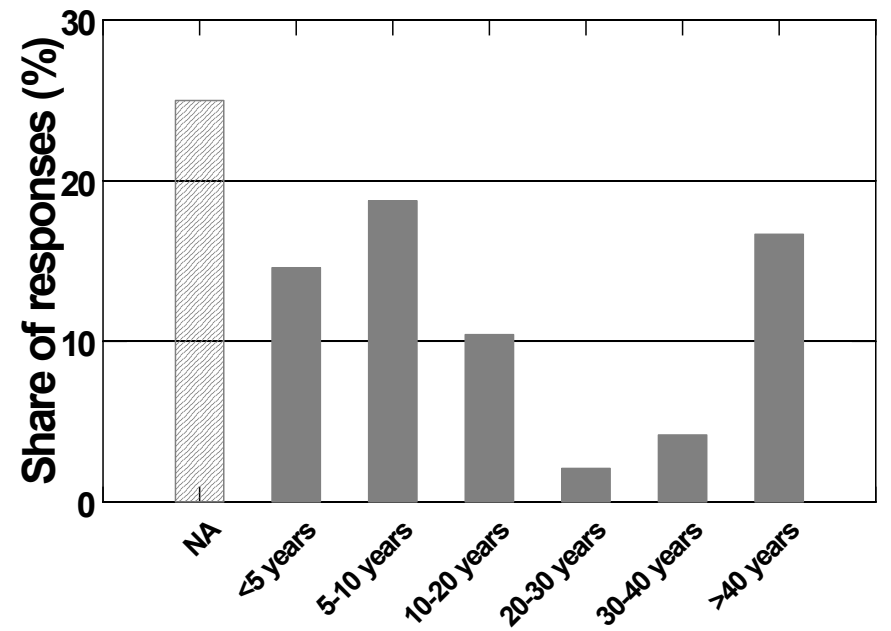

343 Figure 3. Time span of operational usage of aerial photographs within a NFI programme.

\subsection{Use of satellite images to support NFIs}

\subsubsection{Satellite sensor specification and spatial resolution}

The most frequently used satellite systems are medium-resolution satellites: Landsat TM and ETM (13 countries), followed by SPOT 1-5, HR VIR, 
HRG (9 countries), and IRS ( 2 countries). In many countries different satellite

351 sensors have been used simultaneously or for clarification and refinement. Fine

352 resolution satellite imagery such as provided by Quickbird, WorldView 1 and 2 or

353 Geo-Eye-1, is used by only four NFI programmes. Additional spaceborne sensors

354 reported include DMC, MODIS, ALOS, ASTER, SAC-C and Rapid-Eye.

355 Of the respondents using satellite images, $40 \%$ or 18 countries, use

356 satellite data at a national scale with wall-to-wall data coverage. A total of $17 \%(8$

357 countries) of respondents use satellite imagery at sub-national levels or scales.

358 Satellite imagery is often used in combination with auxiliary digital maps, in

359 particular land cover and or land use maps (41\%), topographic maps (30\%),

360 digital elevation models (28\%), and administrative boundary data (24\%) and less

361 so with climatic, ecological, geological, hydrological and soil or land ownership

362 category maps. Approximately $13 \%$ use satellite images to facilitate the

363 assessment of TOF and OWL. A further $45 \%$ of respondents indicate that their

364 NFIs do not collect TOF or OWL information using satellite images.

365 Finland reported the longest operational use of satellite data, having used

366 this technology since the late 1980s. Approximately $17 \%$ or 8 countries

367 responding to the survey have been using satellite imagery for the last 10-20

368 years, five (11\%) countries for 5-10 years, and eight (17\%) countries for fewer

369 than five years.

370 The primary methods used to extract information from satellite images

371 incorporate either prediction and estimation based on image analysis using field

372 data (31\% of respondents or 14 countries) or visual interpretation and expert 
373 knowledge (13\% of respondents or six countries). In Canada, satellite imagery is

374 primarily used to conduct automated image segmentation with subsequent human

375 interpretation of the segmented image. Many estimation techniques are used

376 including supervised parametric (maximum likelihood, discriminant analysis, and

377 linear, nonlinear, and logistic regression) (eight countries) and non-parametric

378 approaches (k-NN), and unsupervised approaches (neural networks, isodata or k-

379 means) (seven countries). Other methods include binary decision trees, fuzzy

380 logic, and object-based image analysis.

\subsubsection{Questionnaire responses}

A total of 13 countries or $29 \%$ of respondents indicate that their NFIs use auxiliary spatial databases to enhance map products constructed using satellite imagery. The most commonly used forms of digital map data used in combination with satellite imagery are land cover/land use maps (41\% or 19 countries), topographic maps (30\% or 14 countries), digital elevation models $(28 \%$ or 13 countries) and administrative boundary data (24\% or 11 countries). Digital map data comprising ownership data, ecological regions, soils or geological data are also used in combination with satellite data. A total of seven countries (16\%) use segmentation techniques to enhance map products. The most commonly produced attribute or thematic maps estimated using remote sensing methods and data from

393 NFI programmes are forest cover or forest area maps (58\% or 26 countries), 394 forest cover type maps (58\% or 26 countries), land cover type maps ( $42 \%$ or 19 countries), and species groups maps (29\% or 13 countries). Biomass, volume, 
396 basal area and height are other themes mapped by NFI programmes using 397 remotely sensed data and associated technologies. Eight countries or $17 \%$ of respondents have used NFI map products constructed using remotely sensed data and technologies to investigate current or past NFI sample designs with a view to introducing efficiencies such as enhanced stratification for variance reduction, stratum size estimation, reduction of field sample sizes and cost savings. Ten countries (22\%) indicated that map products constructed by their NFI programmes serve as input data or validation data for 404 other national land cover map products.

$405 \quad$ Nine $(20 \%)$ countries indicated that map products constructed by their 406 NFIs currently are used in combination with auxiliary spatial data such as 407 administrative data/boundaries to calculate local or small area estimates or map 408 products of forest variables (e.g., volume, height, basal area by administrative 409 unit) where sufficient field data are not available. Furthermore, only 12 countries $410(26 \%)$ indicated attempts to include estimation of uncertainty for parameters 411 estimated from NFI remote sensing-based map products. Finally, only nine 412 countries $(20 \%)$ attempt to include uncertainty estimates of the areal statistics 413 (e.g. error estimates associated with a forest/non-forest area map) in their NFI 414 remote sensing-based map products. In terms of location error, only five countries 415 (11\% of respondents) indicated that either pixel or distance-based error metrics 416 are explicitly accommodated in the map products constructed from NFI data using 417 remotely sensed data and technologies. 


\subsubsection{Future possibilities}

No NFI currently uses data acquired from radar or lidar sensors or unmanned aerial vehicles in an operational manner at a national scale. However, 15 countries indicated an interest in considering use of lidar data in the future. The utility of radar and lidar data has been demonstrated via multiple small-scale and prototype studies using NFI data (e.g., Solberg et al., 2010; Naesset et al., 2011; McRoberts et al., 2012, 2013; Vastaranta et al., 2013; Wulder et al. 2013). The primary impediments to operational implementation at national scales are the cost of acquiring wall-to-wall lidar data for large areas and the cost of providing each field crew with a high grade GPS receiver at a current cost of approximately $\$ 10,000$ (US) per receiver. Use of low density lidar data acquired for constructing digital elevation models may mitigate costs of an initial lidar acquisition for NFI applications as demonstrated by Clement (2002) for the Netherlands, Ginzler et al. (2007) for Switzerland, and Nord-Larsen and Riis-Nielsen (2010) for Denmark; however, the cost of subsequent acquisitions must still be addressed. Until the cost issue can be resolved, possibly via a future spaceborne sensor, operational use of wall-to-wall lidar by NFIs at national scales will likely continue to be limited.

\subsection{Case studies}

Case studies for Switzerland, Finland and the USA illustrate approaches for using remotely sensed data to support NFIs that are state-of-the-art with respect to innovation, statistical rigor and cost efficiency. 


\subsubsection{Switzerland}

Although the Swiss NFI does not wholly depend on the interpretation of

445 aerial images, foregoing the use of aerial photography would result in excessive

446 and unsustainable costs for the ground-based field survey component of the NFI.

447 Since the introduction of aerial imagery to the NFI, the image processing chain

448 has been optimised to reduce the number of plots requiring visual interpretation.

449 However, the time necessary to accomplish the photogrammetric tasks including

450 pre-processing, preparation, optimisation and image interpretation is not

451 insignificant at more than four months per year. Currently, all photogrammetric

452 analysis is conducted by three technicians and two researchers. Data from

453 spaceborne sensors are not currently used operationally by the Swiss NFI because

454 of the limited temporal and spatial resolution of current satellite data products and

455 their limited applicability and usability in Swiss topographic conditions that

456 include relief-induced cloud cover or shadow and/or geometric correction issues

457 over large areas as a result of steep terrain.

458 The Swiss NFI is a sample-based survey that has been conducted every 10

459 years since 1983 (NFI1). With the initiation of NFI2 in 1993, only half of the

460 original sample plots (approximately 6500 plots) have been visited in the field

461 because the $1-\mathrm{km}$ width of the NFI1 sampling grid was extended to $1.4 \mathrm{~km}$. To

462 compensate for the reduced sampling intensity, aerial images were visually

463 interpreted using a 500-m x 500-m regular grid. The black and white aerial

464 imagery used for both NFI1 (1983-1985) and NFI2 (1993-1995) was replaced by 
scanned aerial colour imagery for NFI3 (2003-2007). Similar interpretation methods are being used for NFI4 (2009-2017) which is based on a continuous survey with plots surveyed over a period of nine years as opposed to a periodic survey. Thus, one-ninth of the sample plots systematically distributed over the land area of Switzerland are stereo-interpreted every year using digital aerial images. The aerial imagery was acquired by The Federal Office of Topography (swisstopo) and has been available for the entire country since 2008. This aerial

472 imagery is currently being acquired on a 3-year cycle.

473 For NFI1 and NFI2, black and white 1:25,000 scale aerial film images were 474 stereo-interpreted using analytic stereo-equipment. The aims of photo475 interpretation were to reduce costs for the field survey by identifying plots clearly 476 outside forest. In the third inventory (Ginzler et al., 2005), black and white images 477 were replaced by scanned aerial true colour images at a scale of approximately 478 1:30,000 captured using a Leica RC30 aerial sensor. The stereo-interpretation of 479 plots was conducted using 3D computer screens with polarized eyeglasses and 480 included the follow steps:

- identification of the forest boundary (if any)

- assessment of forest/ non-forest at the centre point of the plot

- assessment of height and land cover type (11 categories) at 25 subsampling points within a 50x50m square in a regular 500m raster (Figure 4)

- for forest plots the assessment of the forest type (six categories) 
- for non-forest plots the assessment of tree attributes outside forest (height measurements of individual trees/length measurements of hedges, groups of trees)

- for forest plots on the sub-grid on the terrestrial inventory the identification and coordinates of orientation points for field crews.

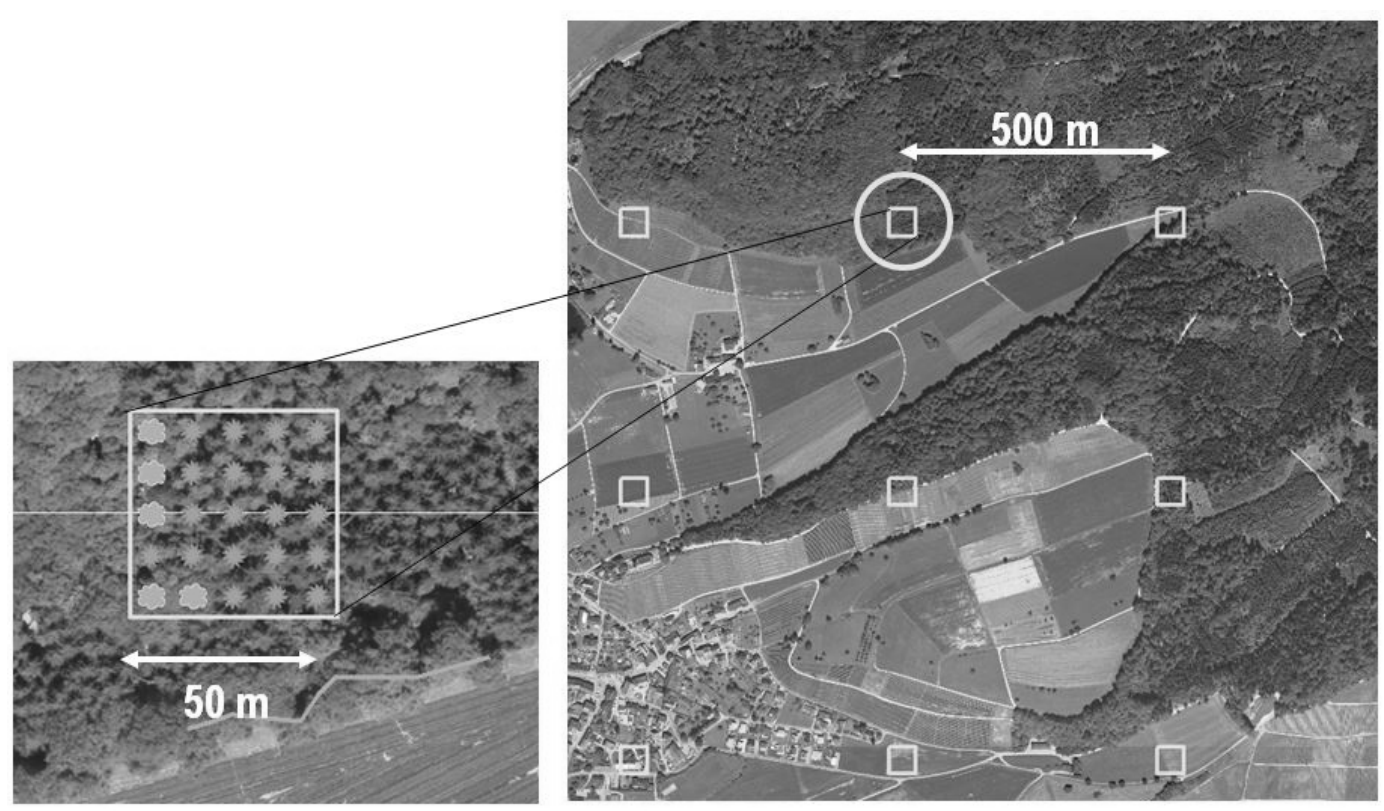

Figure 4. Interpretation of 25 sub-sampling points of a $500 \mathrm{~m}$ regular raster for tree/non-tree, and deciduous/coniferous species decisions.

497 using multispectral (RGBI) digital aerial images from the Lecia Airborne Digital 498 ADS80 sensor with a spatial resolution of $25 \mathrm{~cm}$ in areas of flat topography, and $49950 \mathrm{~cm}$ in mountainous areas of the Alps. Aerial image interpretation includes estimation of TOF resources for biomass estimation, analysis of landscape patterns and diversity including woodland shape and connectivity, as well as 
estimation of tree heights and tree volume for small areas. OWL is considered part

503 of the forest in Switzerland, whereas forest cover on other lands such as

504 cemeteries, parks, and plantations that otherwise satisfy the definition of forest are

505 not yet considered in the photo interpretation exercise.

506 To date, NFI map outputs constructed with the support of remotely sensed 507 data have not been used to investigate the efficacy of the NFI sample design.

508 However, future NFI plans incorporating aerial imagery include the reduction of 509 the field sample size by means of automated routines for the elimination of non510 forest plots and the implementation of double sampling for post-stratification to 511 reduce estimation errors. In the future, estimation will be pixel-based to facilitate 512 map construction. Furthermore, there will be an increased focus on enhanced 513 statistical tools (i.e. generalized regression estimators and plot updating) to 514 increase the reliability and utility of map products (e.g., Massey et al., 2014). 515 Automation of the production chain to combine both the country-wide available 516 images from the Leica ADS80 Airborne Digital Sensor and the Swiss vegetation 517 height model (Ginzler \& Hobi, 2015) will facilitate construction of wall-to-wall 518 forest map products such as a national forest mask, a national tree height strata 519 map and degree of mixture (of species) maps. The VHM is the product of digital 520 surface model, a thresholded Normalized Difference Vegetation Index (NDVI) (to 521 separate vegetation from non-vegetation) and a LiDAR digital terrain model. 522 Initial testing to automate production of these types of maps has produced 523 promising results. 

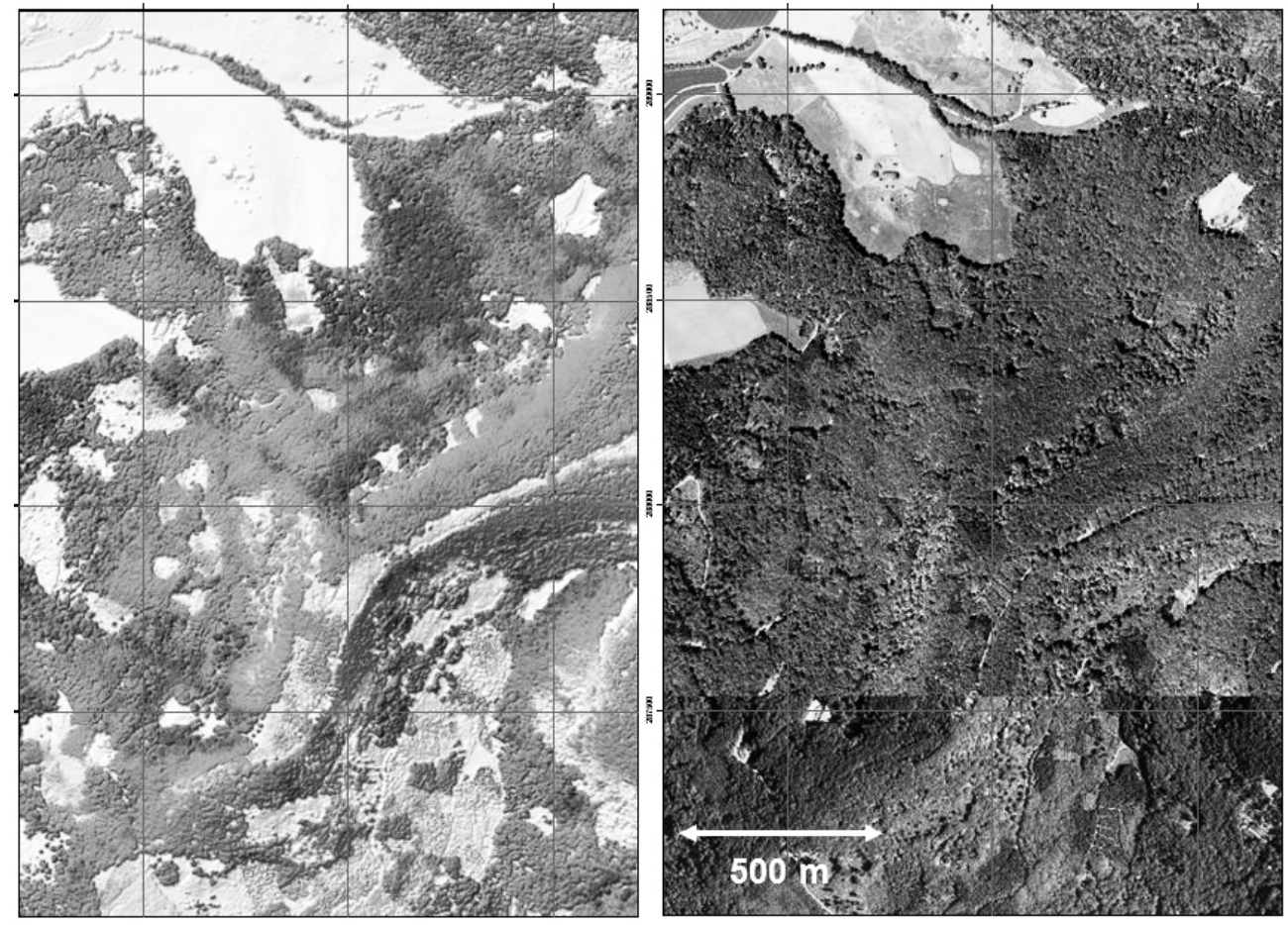

Figure 5. Example of the Swiss vegetation height model (VHM) (left) and the dark grey (high, e.g. mature forest).

\subsubsection{Finland}

The first Finnish NFI, NFI1, was conducted from 1921-24. Areas of site class, stand class, as well as growing stock were estimated using line sampling, and plot measurements were used to calibrate ocular estimates of stand volume

534 and increment. Aerial photographs were first introduced and analysed in 535 combination with field plot data in northern Finland during NFI5 (1964-1970) 536 (Poso, 1972) with the inventory completed by region. NFI6 (1971-1976) saw the 
537 introduction of aerial photography for two-phase sampling in large areas of 538 Lapland.

For NFI10 (2004-2008), NFI11 (2009-2013), and NFI12 (2014-present)

540 field sample plots were surveyed across the entire country, except for Åland and

541 North Lapland, using a new panel system, and the inventory cycle was shortened

542 from almost 10 to five years. The current sample plot density is sufficiently large

543 to ensure that the resulting error estimates are small for the estimates of the core

544 variables for the entire country or regions for area of forest land and growing

545 stock. For example, the standard error of the estimate of growing stock volume for

546 a land area of 0.8 to 5.0 million ha is approximately $2 \%$, and at the national level 547 is $0.6 \%$ (Tomppo et al., 2011).

548 The development of the Finnish MS-NFI began in 1989 during NFI8, with 549 the first results calculated in 1990 and later for the entire country during the years 550 1990-1994 (Tomppo, 1991; Tomppo et al. 2008a,b, 2011, 2014). For the first MS551 NFI, satellite image analysis methods were sought that would provide forest area 552 and volume estimates that could be disaggregated into subclasses such as tree 553 species, timber assortments, and stand-age classes. A further requirement for the 554 MS-NFI method was cost-efficient estimates of forest resources for areas smaller 555 than would be possible using field data alone, typically areas of 1000 s to hundreds 556 of 1000 s of ha.

557 In the first experiments, regression analysis and discriminant analysis were 558 tested (Tomppo, 1988). Variables had to be predicted separately (or in small 559 groups) in these approaches. These tests produced two main findings: 1) it was 
difficult to obtain a sufficient degree of detail in the information in discriminant or

561 similar analyses, and 2) the dependence structure among the estimates generally

562 was lost when estimates of different parameters were made independently. To

563 avoid these drawbacks, the MS-NFI method using field plot data, satellite images

564 and digital map data, and the k-NN technique (Fix and Hodges, 1951; Tomppo

565 1991) was developed. Following the initial implementation, the k-NN estimation

566 technique has been modified continuously and new features have been added

567 (Katila et al., 2000; Katila and Tomppo, 2001). The core of the current Finnish

568 method is presented in Tomppo and Halme (2004) which summarises the two key

569 ideas of the approach: 1) the use of coarse scale variables in directing the selection

570 of the neighbours, and 2) the weighting of the explanatory variables, i.e., spectral

571 variables, coarse scale variables and possible map variables by means of a genetic

572 algorithm optimisation technique. Any digital land use map or land cover data can

573 be used to improve the accuracy of the predictions (Tomppo, 1991). The Landsat

574 sensors (MSS/TM/ETM+/OLI) have been the principle source of satellite imagery

575 used for k-NN estimation in Finland.

576 The nonparametric k-NN estimation uses a distance metric defined in the

577 the feature space of the remotely sensed and possibly other auxiliary variables.

578 Positive weights are given to observations for the $\mathrm{k}$ plots that are nearest or most

579 similar to a prediction unit with respect to the distance metric, and zero weights 580 are given to the other plots (e.g., Tomppo, 2008a). The weights are typically

581 either equal for each of the $\mathrm{k}$ nearest plots or are inversely proportional to the

582 distance or a power of the distance. The weights are then added over areal 
estimation units such as municipalities (Tomppo et al., 2008, Eqs. 3.12 and 3.13).

584 The plot weights, also called plot expansion factors, can be interpreted to be 585 proportional to the inverses of the new inclusion probabilities for the field plots. 586 Because field plots external to the areal estimation unit (e.g., a municipality) can 587 also have positive inclusion probabilities, k-NN estimation can be considered to 588 be a form of synthetic estimation. The recalculated inclusion probabilities 589 facilitate use of ratio estimators for calculating the final forest resource estimates 590 (Tomppo et al., 2008, Eq. 3.14). In principle, estimates are possible for the entire 591 suite of inventory parameters that are otherwise calculated using only the field 592 plot data. In addition to areal units, estimates are often calculated for individual pixels as weighted averages of the of the observations of the variable of interest for the $\mathrm{k}$ nearest plots.

This procedure has been the core of the estimation method in the Finnish MS-NFI for calculating the estimates for areal units, in practice municipalities 597 (Tomppo et al., 2008a). Although the basic principle of k-NN estimation is straightforward, practice has shown that the predictions and estimation errors depend largely on the core estimation parameters of the k-NN algorithm and the selections made in estimation (Tomppo et al. 2008a, 2014).

To date, six sets of MS-NFI results have been produced for Finland at both country and regional levels. The sixth set of results, corresponding to the year 2011, were published in 2014 (Tomppo et al., 2014). The pixel level estimates in 604 the form of digital maps are currently publicly available (Luke, 2015) with file 
606 Finland, 2015). In the future, national level estimates are expected to be

607 generated every second year, and then annually when country-wide satellite 608 imagery becomes available.

609 Similar k-NN methods that combine field plot data and satellite imagery 610 have been developed in several other countries including Sweden, the USA, 611 Norway, Austria, New Zealand, Italy and China. More recently, the Finnish 612 improved k-NN (ik-NN) method, which includes a genetic optimisation 613 algorithm, has been successfully applied to areas in Ireland, Boznia and 614 Herzegovina and Spain as part of the research conducted by WG2.

\subsubsection{United States of America} The Forest Inventory and Analysis (FIA) programme of the U.S. Forest

618 Service conducts the NFI of the USA. Inventory estimates produced by the 619 programme are subject to precision requirements (USDA-FS, 1970) that are 620 difficult to satisfy using plot data alone because of natural variability and 621 budgetary constraints that limit sample sizes. In response, the FIA programme 622 has a long history of augmenting ground sample data with remotely sensed data to 623 compensate for sample size constraints. Historically, the programme used aerial 624 photography and double sampling for stratification to increase the precision of 625 inventory estimates (Loetsch \& Haller, 1964; Hansen, 1990). In the first phase, an 626 array of points or photo plots on the aerial photographs was visually interpreted 627 and assigned to similarity groups or strata based on interpreted features such as 628 forest type and age class. The proportions of photo plots assigned to strata were 
used as stratum weights. In the second phase, field crews visited plots located at a

630 subset of the locations of the photo plots and obtained observations and 631 measurements of plot attributes. Using data obtained from this double-sampling 632 approach, inventory parameters were estimated using post-stratified estimators 633 (Cochran, 1977).

634 The essence of stratified estimation is to group plots into strata, calculate 635 within-strata estimates, and then calculate overall estimates as weighted averages 636 of the within-strata estimates. If the within-strata means differ substantially or 637 highly variable plots can be constrained to small strata, then the precision of the 638 stratified estimates may be substantially greater than the precision of simple 639 random sampling estimates. If the stratification is accomplished prior to 640 sampling, then maximum precision can be achieved by selecting within-strata 641 sampling intensities proportional to the within-strata variances and using stratified 642 random sampling. However, if the sampling intensity is constant over large 643 regions, such as is typically the case with systematic samples of permanent plots, 644 then considerable increase in precision can still be achieved using post645 stratification techniques.

646 In the early 1990s, the FIA programme sought alternatives to aerial 647 photographs as a source of information for constructing strata because of labor 648 intensity, subjectivity, and costs. In Finland, Poso et al $(1984,1987)$ had 649 previously used stratifications based on unsupervised classifications of satellite 650 data. Muinonen and Tokola (1990) further considered the satellite image 651 information to constitute complete coverage of the area of interest rather than just 
652 a first-phase sample. With this approach, two tasks must be accomplished: firstly, 653 strata weights must be calculated as the relative proportions of pixels assigned to 654 strata, and secondly, plots must be assigned to the strata of the pixels containing 655 their centres. However, for large areas such as states, provinces, and regions, the 656 labour and costs associated with acquiring and processing large amounts of 657 remotely sensed data inhibit this practice. For example, 10-20 Landsat scenes are 658 required to cover individual states in the Midwestern region of the USA.

659 Hansen and Wendt (2000) first proposed using an existing satellite image660 based land cover classification as a source of stratification information. 661 McRoberts et al. (2002b) further refined this approach using the National Land 662 Cover Dataset (NCLD) (Vogelmann et al., 2001; Homer et al., 2004, 2007), a 30$663 \mathrm{~m} \times 30-\mathrm{m}$, multi-class, Landsat-based land cover dataset. The thematic classes of 664 the 1992 NLCD were aggregated to forest and non-forest, and four strata were 665 then constructed: (i) forest, (ii) forest edge defined as a 2-pixel wide buffer on the 666 forest side of the forest/non-forest boundary, (iii) non-forest edge defined as a 2667 pixel wide buffer on the non-forest side of the forest/non-forest boundary, and (iv) 668 non-forest. This approach to stratified estimation reduced variances of estimates 669 of proportion forest area by factors as great as 3.2 for four Midwestern states and 670 was operationally implemented by some of the regional FIA programmes.

671 McRoberts et al. (2006) later showed that stratifications based on 672 estimates of pixel-level probabilities of forest cover reduced variances of 673 estimates of proportion forest by factors as great as 5.9 and variances of estimates 674 of mean growing stock volume per unit area by factors as great as 2.5 . The 
675 similarity between the probability of forest cover and the percent tree canopy 676 cover layer for the 2001 NLCD facilitated operational implementation of the latter 677 approach to stratification. These variance reduction factors are equivalent to the 678 factors by which sample sizes would have to be increased to achieve the same 679 precision without the use of remotely sensed data as was achieved with the 680 remotely sensed data. These cost savings are typically substantial.

681

\subsection{Good practice guidelines}

For countries initiating, expanding, or revising use of remotely sensed data in their NFIs, lessons learned from the responses to the questionnaire, the case studies, and the experiences of other NFI programmes can be extremely useful. To assist and facilitate such efforts, a few good practice guidelines are provided. If NFI plot data are to be combined with satellite data with fixed resolution, the relative sizes of the plots and the pixels should be considered. A 689 first consideration pertains to whether the pixel resolution is finer than or coarser 690 than the plot size. If the resolution is finer than the plot size, then the issue relates to methods for aggregating data for multiple spectral bands for multiple pixels to match as closely as possible the plot area. If the image resolution is coarser than 693 the plot size, which is typically the case for commonly used Landsat and SPOT 694 data, then the issue is the degree to which the plot is an adequate sample of the 695 pixel. In addition, if the plot includes multiple conditions related to factors such

696 as forest/non-forest, forest type, or forest age and structure, then the condition 697 proportion for the smaller plot cannot be assumed to represent the same 
698 proportion for the larger pixel. Thus, deletion of some plots from the analyses

699 may become necessary.

700 Whenever data from multiple sources are combined, issues of geo701 rectification must be considered. For example, correctly matching pixels to plots 702 whose GPS location errors are of the same order of magnitude as pixel 703 dimensions is a difficult task, and errors may have adverse consequences, 704 particularly for fragmented and diverse forest conditions.

A second issue related to combining data from multiple sources pertains to 706 dates. To the degree possible, dates of remotely sensed data should be as close as 707 possible to field plot measurement dates. Plot-level disturbances caused by 708 harvest, storm damage, and insect and disease between the two dates can cause 709 large errors in estimates and map products. Plots with such large changes should 710 be either up-dated or removed from the analyses. Growth models may be applied 711 to update data for plots that were measured in years before image acquisition 712 (Tomppo et al., 2014).

713 Ranges of variation in both response and remotely sensed variables in the 714 sample or training data should cover ranges in the same variables in the entire 715 inventory area of interest. Predictions from non-parametric methods such as k$716 \mathrm{NN}$ are especially susceptible to extrapolation errors resulting from inadequate 717 sample ranges in the response and remotely sensed variables. If consistent maps of multiple inventory variables are desired, then all map variables should be predicted for map units simultaneously and in a consistent 
manner using a multivariate method such as the k-NN technique (Tomppo et al.,

721 2008a; McRoberts, 2012).

Adequate, if not optimal, combinations of NFI field data, remotely sensed

723 data, and analytical methods should be sought. The choice of adequate imagery,

724 whether from airborne or spaceborne sensors, for an NFI depends on multiple

725 theoretical, technical and practical considerations. From a technical perspective,

726 the input data must provide the required accuracy for estimates using the selected

727 analytical methods. This requirement may limit the acceptable spatial, spectral

728 and radiometric resolutions. From a practical perspective, choices may be further

729 limited by data availability and costs and analytical expertise within the NFI

730 programme. Spatial considerations are also relevant; for example, combinations

731 that provide sufficiently accurate results for small areas, may not do so at the

732 national level. Revision and iterative testing of plot configurations, sample

733 designs and sample sizes may be necessary to optimize the benefits from remotely

734 sensed data relative to costs.

735 The uncertainty in forest attribute maps and map-assisted estimates should be

736 estimated using statistically rigorous methods. For example, methods based on

737 pixel-counting, such as estimating forest area as the sum of areas of pixels

738 classified as forest, are inherently biased because of map prediction errors. All

739 map-based estimates must be adjusted to compensate for prediction errors,

740 typically by comparing map predictions and ground data for a probability sample

741 using techniques such as the model-assisted, generalized regression estimator

742 (Särndal et al. 1992, Section 6.5; McRoberts et al., 2014). 


\section{4. Conclusions}

745 Four main conclusions may be drawn from the responses to the questionnaire 746 and the case studies. Firstly, remote sensing is now a central component for the 747 successful operation and completion of NFIs. A wide range of traditional as well 748 as new statistical techniques have been used in the analysis of remotely sensed

749 data, in combination with NFI field inventory data. At the same time, a variety of 750 auxiliary datasets have also been included and combined with NFI plot data using 751 remote sensing methods to improve the estimation of forest parameters and 752 variables through pre and post-stratification approaches.

753 Secondly, the levels of detail, scale and approaches used in NFIs vary 754 considerably. Methods are adapted nationally, regionally or locally and are 755 tailored to match the specific topographic, bio-climatic zones and or forest types 756 of the areas being assessed.

757 Thirdly, while the application of remote sensing methods within NFI 758 programmes has contributed to maximizing benefits relative to costs, operational 759 integration of uncertainly estimation requires additional attention.

760 Fourthly, COST Action FP101 provided an effective forum for exchanging 761 information and transferring expertise. For example, methods developed and used 762 operationally in Finland have been modified and developed for Irish conditions 763 (McInerney et al., 2014), and are under modification for transfer to Bosnia and 764 Herzegovina and Spain. 


\section{Acknowledgements}

767 This article is a product of Working Group 2 of COST Action FP1001

768 (USEWOOD). COST (European Cooperation in Scientific and Technical

769 Research), financially supported the meetings and Short Term Scientific Missions

770 making this work possible. We thank the respondents from 45 countries who

771 participated in our questionnaire survey: Alberto Sandoval Uribe, Jacques

772 Rondeux, Marc Wagner, Celina Montenegro, Conceição Moreno, Paul Lane,

773 Claire Howell, Georgios A. Georgiou, José Uva, Marko Kovac, Novica Tmusic,

774 Yasna Rojas Ponce, Emine Ataş, Marek Jabłoński, Nickola Stoyanov, Nicholas

775 Py, Azra Čabaravdić, Zsolt Magyar, Sung-Ho Kim, Graham Stinson, Annemarie

776 Bastrup-Birk, Vivian K. Johannsen, Joberto Veloso de Freitas, Juris Zarins, Mark

777 Lawrence, Xiangdong Lei, Björn Traustason, Daniel Nitu, Lars Waser, Veiko

778 Adermann, Wim P. Daamen, Christoph Bauerhansl, Tomáš Bucha, Mats Nilsson,

779 Yasumasa Hirata, Gerald Kändler, Heino Polley, Erkki Tomppo, Ronald E.

780 McRoberts, Radim Adolt, Svein Solberg, Ioannis Meliadis, Julien Philippart,

781 Patrizia Gasparini, Santiago Saura, Gintautas Mozgeris, Tatiana Chernenkova,

782 Christian Ginzler. 
784 Bickford, C.A. (1952). The sampling design used in the forest survey of the 785 northeast. Journal of Forestry, 50, 290-293.

786 Brassel, P. \& Lischke, H. (eds.). (2001). Swiss National Forest Inventory:

787 Methods and Models of the Second Assessment. Birmensdorf, Swiss. Federal

788 Research Institute WSL.

789 Cienciala, E., Tomppo E., Snorrason, A., Broadmeadow, M., Colin, A., Dunger,

790 K., Exnerova, Z., Lasserre, B., Petersson, H., Priwitzer, T., Sanchez, G. \& Ståhl,

791 G. (2008). Preparing emission reporting from forests: use of National Forest

792 Inventories in European countries. Silva Fennica, 42, 73-88.

793 Clement, J. (2003). LiDAR derived 3D forest stand parameters of Dutch pine.

794 Thesis, Wageningen University, the Netherlands. 64 pp.

795 Cochran, W.G. (1977). Sampling techniques (3rd ed.). Wiley, New York.

796 COST. (2014). European Cooperation in Science and Technology. Available at:

797 http://www.cost.eu. Last accessed: June 1015.

798 COST FP1001. (2014) USEWOOD: Improving data and information on the

799 potential supply of wood resources, a European approach from multisource

800 national forest inventories. Available at:

$801 \mathrm{https}: / /$ sites.google.com/site/costactionfp1001/. Last accessed: June 2015.

802 Danson, F.M. (1987). Preliminary evaluation of the relationships between SPOT-

$8031 \mathrm{HRV}$ data and forest stand parameters. International Journal of Remote Sensing,

$8048,1571-1575$.

805 FAO. (2008). Technical Review of FAO's Approach and Methods for National

806 Forest Monitoring and Assessment (NFMA). By Erkki Tomppo and Krister

807 Andersson. National Forest Monitoring and Assessment Working Paper NFMA

808 38. Rome.

809 FAO. (2010). Global Forest Resources Assessment 2010. Main Report. FAO

810 Forestry Paper 163. FAO, Rome.

811 Fix, E., \& Hodges J.L. (1951). Discriminatory analysis - nonparametric

812 discrimination: consistency properties. Report no. 4. Random Field, Texas, USA:

813 USAF of Aviation Medicine. Randolph Field, Texas.

814 Foresta, H. de, Somarriba, E., Temu, A., Boulanger, D., Feuilly, H. \& Gauthier,

815 M. (2013). Towards the Assessment of Trees Outside Forests. Resources

816 Assessment Working Paper 183. FAO, Rome

817 Franco-Lopez, H., Ek, A.R. \& Bauer, M.E. (2001). Estimation and mapping of

818 forest stand density, volume, and cover type using the k-nearest neighbors

819 method. Remote Sensing of Environment, 77, 251-274. 
820 Ginzler, C., Bärtschi, H., Bedolla, A., Brassel, P., Hägeli, M., Hauser, M.,

821 Kamphues, M., Laranjeiro, L., Mathys, L., Uebersax, D., Weber, E., Wicki P., \&

822 Zulliger, D. (2005). Luftbildinterpretation LFI3 - Interpretationsanleitung zum

823 dritten Landesforstinventar. Birmensdorf, Eidg. Forschungsanstalt für Wald,

824 Schnee und Landschaft WSL. 87 S.

825 Ginzler, C., \& Hobi, M.L. (2015). Countrywide stereo-image matching for

826 Updating Digital Surface Models in the Framework of the Swiss National Forest

827 Inventory. Remote Sensing 7, 4343-4370.

828 Ginzler, C., Boehl, J., Boesch, R., \& Waser, L.T. (2007). Accuracy of forest

829 parameters derived from medium footprint lidar under operational constraints.

830 Proceedings of ISPRS Workshop on Laser Scanning 2007 and SilviLaser 2007.

831 Espoo, Finland. September 12-14, 2007.

832 Gjertsen, A. (2007). Accuracy of forest mapping based on Landsat TM data and a

833 kNN-based method. Remote Sensing of Environment, 110, 420-430.

834 Hajnsek, I., Kugler, F., Seungkuk, L. \& Papathanassiou, K. (2009). Tropical

835 Forest Parameter Estimation by means of Pol-InSAR: The INDREX-II Campaign.

836 IEEE Transactions on Geoscience and Remote Sensing, 47, 481-493.

837 Halme, T. \& Tomppo, E. (1987). Stand-based forest inventory from satellite

838 images. General description. In: Remote Sensing-Aided Forest Inventory.

839 University of Helsinki, Department of Forest Mensuration and Management,

840 Research Notes No. 19, 45-46.

841 Hansen, M. H. (1990). A comprehensive sampling system for forest inventory

842 based on an individual tree growth model. $\mathrm{PhD}$ dissertation. St. Paul, MN:

843 University of Minnesota, College of Natural Resources.

844 Hansen, M.H. \& Wendt, D.G. (2000). Using classified Landsat Thematic Mapper

845 data for stratification in a statewide forest inventory. In: McRoberts, R.E., Reams,

846 G.A., Van Deusen, P.C. (eds.). Proceedings of the First Annual Forest Inventory

847 and Analysis Symposium. 2-3 November 1999, San Antonio, Texas. U.S. Forest

848 Service General Technical Report NC-213, 20-27.

849 Homer, C. Huang, C. Yang, L., Wylie, B. \& Coan, M. (2004). Development of a

8502001 national land cover database for the United States. Photogrammetric

851 Engineering and Remote Sensing, 70, 829-840.

852 Homer, C., Dewitz, J., Fry. J., Coan, M,. Hossain, N., Larson, C., Herold, N.,

853 McKerrow, A., Van Driel, J.N., \& Wickham, J. (2007). Completion of the 2001

854 national land cover database for the conterminous United States.

855 Photogrammetric Engineering and Remote Sensing, 73, 337-341.

856 Katila, M., Heikkinen, J., \& Tomppo, E. (2000). Calibration of small-area

857 estimates for map errors in multisource forest inventory. Canadian Journal of

858 Forest Research, 30, 1329-1339. 
Katila, M., \& Tomppo, E. (2001). Selecting estimation parameters for the Finnish multisource National Forest Inventory. Remote Sensing of Environment, 76, 1632.

Koch, B. (2013). Remote sensing supporting national forest inventories. In: FAO Knowledge Reference for National Forest Assessments. Available at:

http://www.fao.org/fileadmin/user_upload/national_forest_assessment/images/PD Fs/English/KR2_EN_8_.pdf.

Köhl, M. \& Päivinen, R. (1996). Definition of a system of nomenclature for mapping European forests and for compiling a Pan-European Forest Information System. Final Report of the Project. Luxembourg: Office for Official Publications of the European Communities.

Köhl, M., Magnussen, S.S., \& Marchetti, M. (2006). Sampling methods, remote sensing, and GIS multiresource forest inventory. Springer, Berlin.

Koukal, T., Suppan, F., \& Schneider, W. (2007). The impact of relative radiometric calibration on the accuracy of $\mathrm{kNN}$-predictions of forest attributes. Remote Sensing of Environment, 110, 431-437.

LaBau, V.J., Bones, J.T., Kingsley, N.P., Lund, G.H. \& Smith, W.B. (2007). A History of the Forest Survey in the United States: 1830-2004. United States Department of Agriculture. Forest Service FS-877.

Lawrence, M., McRoberts, R.E., Tomppo, E., Gschwantner, T. \& Gabler, K. (2010). Chapter 2, Comparisons of National Forest Inventories, 19-32. In: Tomppo, E., Gschwantner, T., Lawrence, M. \& McRoberts, R.E. (eds.). National Forest Inventories - Pathways for common reporting. Springer, Heidelberg Dordrecht London New York.

Loetsch, F. \& Haller, K.E. (1964). Forest inventory: vol. 1. Statistics of forest inventory and information from aerial photographs. Munchen, Germany: BLV Verlagsgesellschaft.

Loveland, T.R \& Hansen, M.C. (2012). Chapter 4, Global Data Availability from U.S. Satellites: Landsat and MODIS, 69-78., in: Global Forest Monitoring from Earth Observation. CRC Press.

Luke. (2015). File service for publicly available data. Available at: http://kartta.metla.fi/index-en.html. Last accessed Jun 28, 2015.

Martinez, M. \& Condes, S. (1997). Country report for Spain. In: Päivinen, R., Köhl, M. (eds). Study on European Forestry Information and Communication System, European Commission. Office for official publications of the European Communities. Reports on forestry inventory and survey systems. Vols. 1 and 2.

Maselli, F., Chirici, G., Bottai, L., Corona, P. \& Marchetti, M. (2005). Estimation of Mediterranean forest attributes by the application of $\mathrm{k}-\mathrm{NN}$ procedures to multitemporal Landsat ETM+ images. International Journal of Remote Sensing, 17, 3781-3796. 
Massey, A., Mandallaz, D., \& Lanz. A. (2014). Integrating remote sensing and past inventory data under the new annual design of the Swiss National Forest Inventory using three-phase design-based regression estimation. Canadian Journal of Forest Research, 44, 1177-1186.

McInerney, D., Pekkarinen, A., \& Haakana, M. (2005). Combining Landsat ETM+ with field data for Ireland's national forest inventory - A pilot study for Co. Clare. In H. Olsson (ed.), Proceedings of ForestSat 2005. Borås, Sweden, 31 May - 3 June 2005. (pp. 12-16). Available at: http://shop.skogsstyrelsen.se/shop/9098/art92/4646092-23ff72-1740-1.pdf.

McInerney, D., Barrett, F. \& Tomppo, E. (2014). Applying ikNN in Southern Ireland using NFI data. Presented at the Final Meeting of COST Action FP1001, Institut National De L'Information Géographique et Forestière (IGN), Paris, 23/09/2015-24/09/2015.

McRoberts, R.E. (2012). Estimating forest attribute parameters for small areas using nearest neighbors techniques. Forest Ecology and Management, 272, 3-12.

McRoberts, R.E. \& Tomppo, E.O. (2007). Remote sensing support for national forest inventories. Remote Sensing of Environment, 110, 412-419.

McRoberts, R.E., Gobakken, T. \& Næsset, E. (2012). Post-stratified estimation of forest area and growing stock volume using lidar-based stratifications. Remote Sensing of Environment, 125, 157-166.

McRoberts, R.E., Liknes, G.C., \& Domke, G.M. (2014). Using a remote sensingbased, percent tree cover map to enhance forest inventory estimation. Forest Ecology and Management, 331, 12-18.

McRoberts, R.E., Nelson, M.D., \& Wendt D.G. (2002a). Stratified estimation of forest area using satellite imagery, inventory data, and the k-Nearest Neighbors technique. Remote Sensing of Environment, 82, 457-468.

McRoberts, R.E., Næsset, E \& Gobakken, T. (2013). Inference for lidar-assisted estimation of forest growing stock volume. Remote Sensing of Environment, 128, 268-275.

McRoberts. R.E., Wendt, D.G., Nelson, M.D. \& Hansen, M.D. (2002b). Using a land cover classification based on satellite imagery to improve the precision improve the precision of forest inventory area estimates. Remote Sensing of Environment, 81, 36-44.

McRoberts, R.E., Tomppo, E.O., \& Næsset, E. (2010). Advances and emerging issues in national forest inventories. Scandinavian Journal of Forest Research, $25,368-381$.

McRoberts, R.E., Holden, G.R. Nelson, M.D., Liknes, G.C. \& Gormanson, D.D. (2006). Using satellite imagery as ancillary data for increasing the precision of estimates for the Forest Inventory and Analysis program of the USDA Forest Service. Canadian Journal of Forest Research, 36, 2968-2980. 
939 Muinonen, E., \& Tokola, T. (1990). An application of remote sensing for

940 communal forest inventory. In: Sylvander, R. \& Poso, S. (eds.). The usability of

941 remote sensing for forest inventory and planning, proceedings from SNS/IUFRO

942 workshop, Report 4, 35- 42. Umeå, Sweden: Remote Sensing Laboratory,

943 Swedish University of Agricultural Sciences.

944 National Land Survey of Finland. (2015). Paikkatietoikkuna - Geographic

945 information and information about geographic information in Finland and the

946 rest of the world. Available at:

947 http://www.paikkatietoikkuna.fi/web/en/frontpage. Last accessed Jun 28, 2015.

948 Nord-Larsen, T., \& Riis-Nielsen, T. (2010). Developing an airborne laser

949 scanning dominant height model from a countrywide scanning survey and

950 national forest inventory data. Scandinavian Journal of Forest Research, 25(3),

$951262-272$.

952 Naesset, E. (2007). Airborne laser scanning as a method in operational forest

953 inventory: Status of accuracy assessments accomplished in Scandinavia.

954 Scandinavian Journal of Forest Research, 22, 433-442.

955 Næsset, E., Gobakken, T., Solberg, S., Gregoire, T.G., Nelson, R., Ståhl, G., \&

956 Weydahl, D. (2011). Model-assisted regional forest biomass estimation using

957 LiDAR and InSAR as auxiliary data: A case study from a boreal forest area.

958 Remote Sensing of Environment, 115, 3599-3614.

959 Poso, S. (1972). A method of combining photo and field samples in forest

960 inventory. Commununicationes Instituti Forestalis Fenniae, 76, 1-133.

961 Poso, S., Hame, T. \& Paananen, R. (1984). A method of estimating the stand

962 characteristics of a forest compartment using satellite imagery. Silva Fennica, 18,

963 261-292.

964 Poso, S., Paananen, R. \& Similä, M. (1987). Forest inventory by compartments

965 using satellite imagery. Silva Fennica 21, 69-94.

966 Praks, J., Kugler, F., Papathanassiou, K., Hajnsek, I., \& Hallikainen, M. (2007).

967 Height estimation of boreal Forest: interferometric model based inversion at L-

968 and X-band vs. HUTSCAT profiling scatterometer. IEEE Geoscience and Remote

969 Sensing Letters, 4, 466 -470.

970 Reese, H., Nilsson, M., Pahén. T,G, Hagner, O., Joyce. S., Tingelöf, U., Egberth,

971 M. \& Olsson, H. (2003). Countrywide estimates of forest variables using satellite

972 data and field data from the National Forest Inventory. Ambio, 32, 542-548.

973 Solberg, S., Astrup, R., Bollandsås, O.M., Næsset, E., \& Weydahl, D.J. (2010).

974 Deriving forest monitoring variables from X-band InSAR SRTM height.

975 Canadian Journal of Remote Sensing, 36, 68-79.

976 Särndal, C.E., Swensson, B., \& Wretman, J. (1992). Model assisted survey

977 sampling. Springer Series in Statistics. Springer-Verlag, Inc. New York. 
978 Spurr, S. H. (1960). Photogrammetry and Photo-interpretation, $2^{\text {nd }}$ ed. The

979 Ronald Press Company, New York.

980 Tomppo, E. (1988). Standwise forest variate estimation by means of satellite

981 images. In IUFRO S4.02.05 Meeting, August 28 - September 2, 1988, Forest

982 Station Hyytiälä, Finland. University of Helsinki, Department of Forest

983 Mensuration and Management, Research Notes, 21, 103-111.

984 Tomppo, E. (1991). Satellite Image-Based National Forest Inventory of Finland.

985 In: Proceedings of the symposium on Global and Environmental Monitoring,

986 Techniques and Impacts, September 17-21, 1990 Victoria, British Columbia

987 Canada. International Archives of Photogrammetry and Remote Sensing, 28, 419-

988424.

989 Tomppo E., \& Halme, M. (2004). Using coarse scale forest variables as ancillary

990 information and weighting of variables in k-nn estimation: a genetic algorithm

991 approach. Remote Sensing of Environment, 92, 1-20.

992 Tomppo, E., M. Haakana, M. Katila \& Peräsaari, J. (2008a). Multi-source

993 national forest inventory - Methods and applications. Managing Forest

994 Ecosystems, Vol. 18. Dordrecht, The Netherlands: Springer.

995 Tomppo, E., Gschwantner, T., Lawrence, M. \& McRoberts, R.E. (eds.). (2010).

996 National forest inventories pathways for common reporting. Springer, Heidelberg

997 Dordrecht London New York.

998 Tomppo, E., Katila, M., Mäkisara, K., \& Peräsaari, J. (2014). The Multi-source

999 National Forest Inventory of Finland - methods and results 2011. Working Papers

1000 of the Finnish Forest Research Institute 319. Available at

1001 http://www.metla.fi/julkaisut/workingpapers/2014/mwp319.htm.

1002 Tomppo, E., H. Olsson, G. Ståhl, M. Nilsson, O. Hagner \& Katila, M. (2008b).

1003 Combining national forest inventory field plots and remote sensing data for forest 1004 databases. Remote Sensing of Environment, 112, 1982-1999.

1005 Tomppo, E., Heikkinen, J., Henttonen, H.M., Ihalainen, A., Katila, M., Mäkelä, 1006 H., Tuomainen, T. \& Vainikainen, N. (2011). Designing and Conducting a Forest 1007 Inventory - case: 9th National Forest Inventory of Finland, Managing Forest 1008 Ecosystems, Vol. 22. Dordrecht, The Netherlands: Springer.

1009 USDA Forest Service (USDA-FS). (1970). Operational procedures. Forest 1010 Service handbook 4809.11 (Chapter 10, pp. 11 - 1). Washington, DC: USDA 1011 Forest Service.

1012 Vastaranta, M., Wulder, M.A., White, J.C., Pekkarinen, A., Tuominen, S., 1013 Ginzler, C., Kankare, V., Holopainen, M., Hyyppä, J. \& Hyyppä, H. (2013).

1014 Airborne laser scanning and digital stereo imagery measures of forest structure:

1015 comparative results and implications to forest mapping and inventory update.

1016 Canadian Journal of Remote Sensing, 39, 382-395. 
1017 Vibrans, A.C., McRoberts, R.E., Moser, P., \& Nicoletti, A.L. (2013). Using 1018 satellite image-based maps and ground inventory data to estimate the area of the 1019 remaining Atlantic forest in the Brazilian state of Santa Catarina. Remote Sensing 1020 of Environment, 130, 87-95.

1021 Vogelmann, J.E., Howard, S.M., Yang, L., Larson, C.R., Wylie, B.K., \& Van 1022 Driel, J.N. (2001). Completion of the 1990s national land cover data set for the 1023 conterminous United States from Landsat Thematic Mapper data and ancillary 1024 data sources. Photogrammetric Engineering and Remote Sensing, 67, 650-662.

1025 Westinga, E., Bijker, W. \& Dijk, K. van. (1999). User requirements study for 1026 remote sensing based spatial information for the sustainable management of 1027 forests. Technical document 4: User needs assessment for spatial forest 1028 information: results and analysis. International Institute for Aerospace Survey and 1029 Earth Sciences, Enschede, Netherlands.

1030 Winter, S., Chirici, G., McRoberts, R.E., Hauk, E., \& Tomppo, E. (2008).

1031 Possibilities for harmonizing national forest inventory data for use in forest 1032 biodiversity assessments. Forestry, 81, 33-44.

1033 Wulder, M.A., Coops, N.C., Hudak, A.T., Morsdorf, F., Nelson, R., Newnham, G. 1034 \& Vastaranta, M. (2013). Status and prospects for LiDAR remote sensing of 1035 forested ecosystems. Canadian Journal of Remote Sensing, 39, 1-5. 